\title{
Microscopía virtual: una nueva herramienta tecnológica para la enseñanza de la histología y la patología
}

\author{
Virtual microscopy: a new technological tool for teaching histology and pathology \\ Pachamé $\mathrm{AV}^{1^{*}}$, Portiansky EL ${ }^{1}$ \\ ${ }^{1}$ Laboratorio de Análisis de Imágenes. Cátedra de Patología General. Facultad de Ciencias Veterinarias. \\ Universidad Nacional de La Plata. \\ *Correo electrónico del autor: apachame@fcv.unlp.edu.ar
}

\begin{abstract}
Resumen: En el curso de Patología General de la Facultad de Ciencias Veterinarias de la Universidad Nacional de la Plata se está llevando a cabo un proceso de transformación de la docencia, al incorporar recursos tecnológicos de la información y la comunicación con el objetivo de mejorar el aprendizaje de la patología por parte de los estudiantes. El presente trabajo proporciona un enfoque general de la microscopía virtual como un novedoso recurso tecnológico complementario, en la enseñanza de disciplinas en las que se emplea el microscopio.
\end{abstract}

Palabras clave: Recurso didáctico, tecnología informática, digitalización, encadenamiento de imágenes digitales

\begin{abstract}
The General Pathology course from the School of Veterinary Sciences, National University of La Plata, is carrying out a transforming process of teaching by incorporating technological resources of information and communication in order to improve pathology learning by students. This report provides a general approach to virtual microscopy as a novel complementary technological resource in teaching of disciplines based on the use of the microscope.
\end{abstract}

Key words: Teaching resource, information technology, digitization, stitching 


\section{Introducción}

La educación superior, en la sociedad actual, requiere de un proceso de flexibilización con respecto a los métodos tradicionales de la enseñanza, que incluyen la aplicación de tecnologías de la información y la comunicación (TIC) en los procesos de formación del estudiante (Salinas, 2010). Sin embargo, su aplicación implica cambios en la concepción del paradigma de la enseñanza de los profesores, acostumbrados al uso de herramientas tradicionales. Se requiere, además, de cambios administrativos en relación con el diseño y distribución de las aulas y el equipamiento necesario para llevar a cabo estas modificaciones. Todo ello implica cambios en los modelos de enseñanza-aprendizaje hacia un modelo más flexible (Salinas, 2010).

Particularizando en los estudiantes de las asignaturas que emplean el microscopio como herramienta fundamental para la observación de muestras histológicas e histopatológicas, resulta evidente la necesidad de buscar nuevos métodos y técnicas al servicio de la educación superior, que fortalezcan el proceso educativo (Figueroa et al., 2015). En este contexto, surge la posibilidad de incorporar la microscopía virtual (MV) como una nueva estrategia metodológica en cursos de carreras de la salud (Figueroa et al., 2015). El aprendizaje de la organización celular y la estructura de tejidos y órganos, constituye una competencia fundamental en la formación básica de los estudiantes. Si bien la habilidad en el uso de la MV estará dirigida por el profesor, es el estudiante quien debe saber reconocer los distintos elementos tisulares, interpretar su morfología y disposición (Peña Amaro, 2006). Para ello se precisa un bagaje previo de información, que le permita al estudiante tener la capacidad resolutiva para una correcta interpretación de la muestra, tal como sucede en la microscopía convencional (Peña Amaro, 2006).

El ojo humano, a pesar de sus imperfecciones, es la herramienta biológica ideal para capturar las imágenes que posteriormente serán almacenadas, procesadas y analizadas por el sistema nervioso. Lamentablemente, no existe aún un dispositivo que permita extraer y compartir lo que cada individuo observa, de manera directa y en tiempo real. Existe, en cambio, la posibilidad de registrar físicamente diferentes eventos, a través de dispositivos analógicos y digitales que reproducen imágenes. Estos dispositivos son capaces de capturar procesos que ocurren a niveles inalcanzables para el ojo humano, tanto por su dimensión como por su longitud de onda de emisión (Portiansky, 2013).

La MV es una herramienta que puede ser utilizada por todos los cursos que emplean el microscopio como instrumento de observación de diversos materiales biológicos (tejidos y células animales y vegetales) y de elementos inanimados. En el presente trabajo describimos las herramientas y los pasos necesarios para la digitalización de muestras histológicas e histopatológicas, para su posterior observación y análisis mediante sistemas informáticos.

\section{Descripción metodológica}

Para la digitalización de las muestras son necesarios un microscopio, una cámara de video y una computadora que contiene un programa capaz de integrar el registro de la cámara de video en tiempo real. En el Laboratorio de Análisis de Imágenes de la Facultad de Ciencias Veterinarias de la Universidad Nacional de La Plata contamos con un microscopio directo de campo ampliado (Olympus BX53, Japón), en el que se reemplazó la platina convencional por otra de carácter motorizado (Prior Scientific Instruments H101AFI, EE.UU.), que permite los desplazamientos de la misma en los ejes $X, Y$ y $Z$ (Fig. 1). De esta manera, el microscopio permite escanear muestras completas procesadas con diferentes técnicas histológicas, histoquímicas, inmunohistoquímicas y de inmunofluorescencia. Sobre este microscopio trinocular se monta una cámara color de video digital (Olympus DP73, Japón), a través de un adaptador, que en nuestro caso cuenta con una lente reductora de $0,5 X$, lo que permite aumentar el campo de visión de la muestra, reduciendo el aumento del objetivo a la mitad. Esta cámara se conecta a una computadora que contiene el programa cellSens Dimension (Olympus v1.6), que permite capturar las imágenes registradas por la misma. A su vez, el software controla la platina motorizada en los tres ejes del microscopio. El uso de la platina es fundamental para integrar todas las imágenes que se capturan de la muestra que se está observando, mediante un proceso de stitching (anidamiento digital de imágenes capturadas en secuencia).

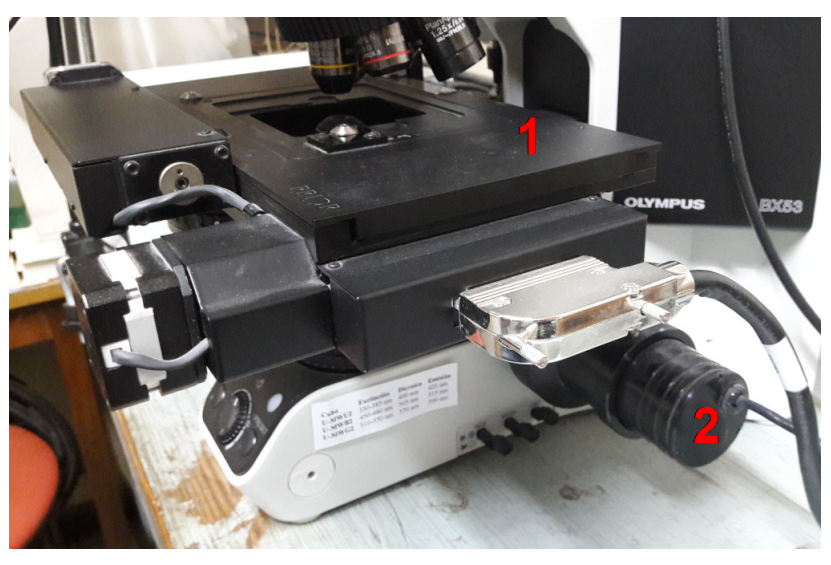

Figura 1. Detalle de la platina motorizada. Microscopio de campo ampliado, directo, en la que se instalaron una platina motorizada (1) que controla los ejes $\mathrm{X}$ e $\mathrm{Y}$ y un dispositivo para movilizar la platina en el eje $Z$ (2). 
Para el escaneo de las muestras (proceso por el cual la platina motorizada se desplaza en los ejes $X e$ $Y$ ), se requiere que en cada paso de desplazamiento (aproximadamente $400 \mu \mathrm{m}$ ) se genere un disparo automático de la cámara de video, lo que permite capturar la imagen que se encuentre enfocada en el eje Z. Para ello, el software cuenta con una función apropiada llamada MIA (del inglés, multiple image alignement). Las imágenes así escaneadas se superponen en un porcentaje ( $10 \%$ en nuestro caso) con la imagen capturada en el paso previo y en la hilera superior. Para la observación posterior, es necesario que el escaneo se realice con la mayor magnificación a la que se quiera arribar. De acuerdo con el grado de resolución que se desee conseguir, el objetivo utilizado será de 20X o 40X, aunque también se pueden utilizar magnificaciones mayores.
La resolución de cada fotograma que forma la imagen final depende de las características de la cámara que se utilice para la captura. En nuestro caso, la resolución de cada imagen individual era de 1600x1200 pixeles, que cubre un área aproximada de $91665 \mu \mathrm{m}^{2}\left(\sim 0,091 \mathrm{~mm}^{2} ; \sim 0,2185 \mu \mathrm{m} / \mathrm{Px}\right)$, si se utiliza un objetivo de 40X, que genera un aumento final de 20X (40X del objetivo multiplicado por 0,5X del adaptador de la cámara). De esa manera, para cubrir $10 \mathrm{~mm}^{2}$ de superficie de un tejido, se requerirán aproximadamente 110 imágenes encadenadas (Fig. 2).

La imagen obtenida del escaneo de la muestra puede ser almacenada en formato TIF, lo que permite que se conserven todas las particularidades de luz y resolución establecidas en el momento de la captura. Esta imagen podrá ser observada con cualquier visualizador, procesador o analizador de imágenes.

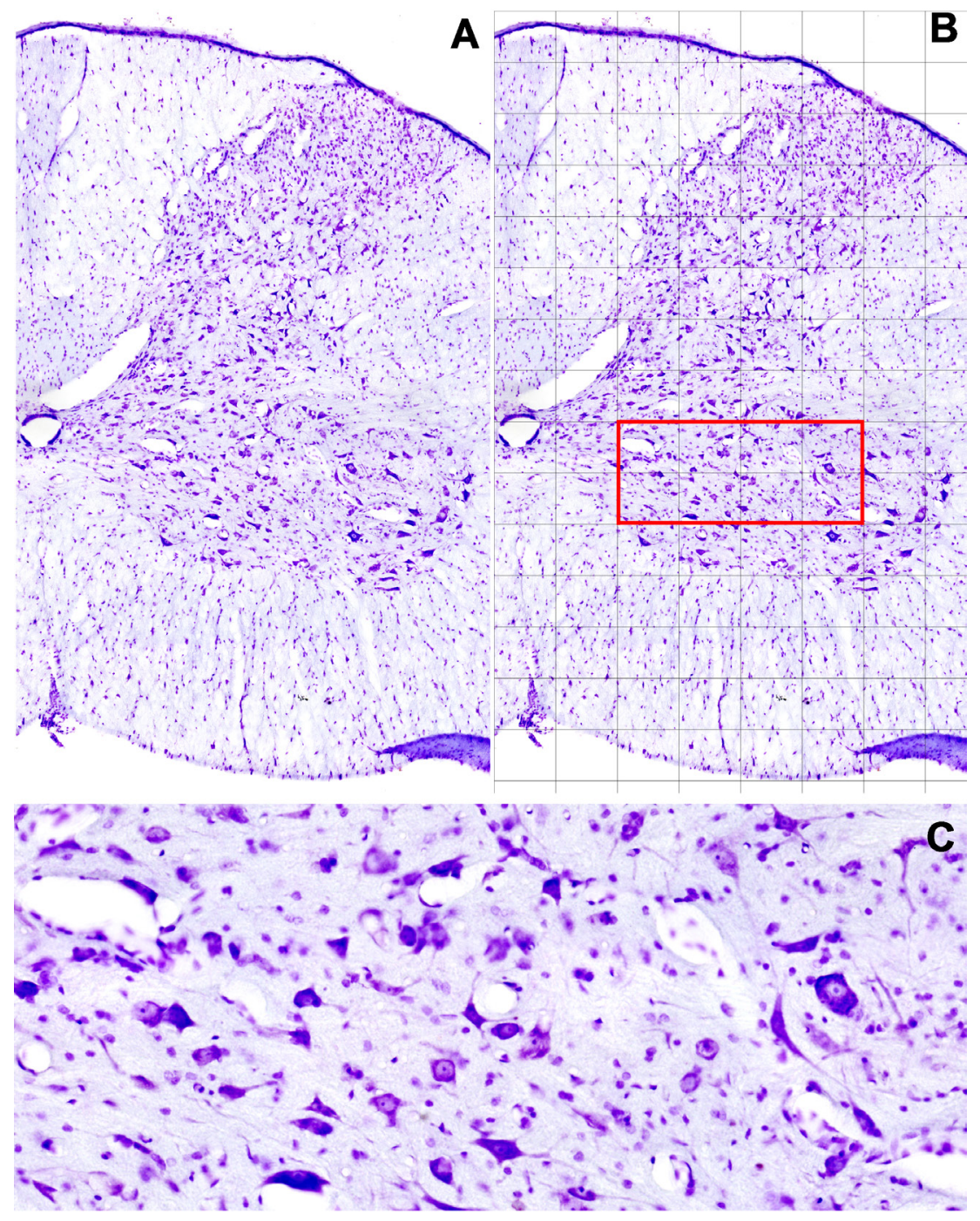

Figura 2. Stitching (anidamiento digital de imágenes capturadas en secuencia) de imágenes de la médula espinal de rata. (A) Hemimédula del segmento C5, escaneada con un aumento final de 20X. (B) La misma imagen (A) segmentada en cada una de los fotogramas individuales utilizados para componer la imagen final. (C) Ampliación de la imagen (B) (recuadro rojo circunscribiendo cuatro columnas y dos filas de imágenes) mostrando que la unión entre las imágenes individuales se hace imperceptible. 
También puede ser almacenada en el formato VSI, propio del software utilizado, que tiene la ventaja de ser interpretado por un visualizador específico de MV, llamado OlyVIA (Olympus). Este visualizador puede ser descargado, de manera gratuita, de la página http:// www.olympus-global.com. Mediante este programa se puede recorrer toda la muestra, desde el menor $(0,5 \mathrm{X})$ hasta el mayor aumento posible (aquel del objetivo del microscopio al que haya sido escaneada la muestra). De esta manera, se podrá integrar toda la muestra y el estudiante podrá recorrer toda la imagen, tal cual lo hubiese hecho con el microscopio (Fig. 3).

\section{Discusión y conclusiones}

Un microscopio virtual puede definirse como el desarrollo de nuevas capacidades digitales que permiten la visión y navegación on line a través de muestras digitalizadas a alta resolución (Mikula et al., 2007). El objetivo principal de la MV es crear la llamada "preparación virtual" o "digitalización de la imagen", guardando toda la información relevante que contiene cada muestra, pero con mayores ventajas que las que brinda el microscopio convencional (García Rojo et al., 2001).

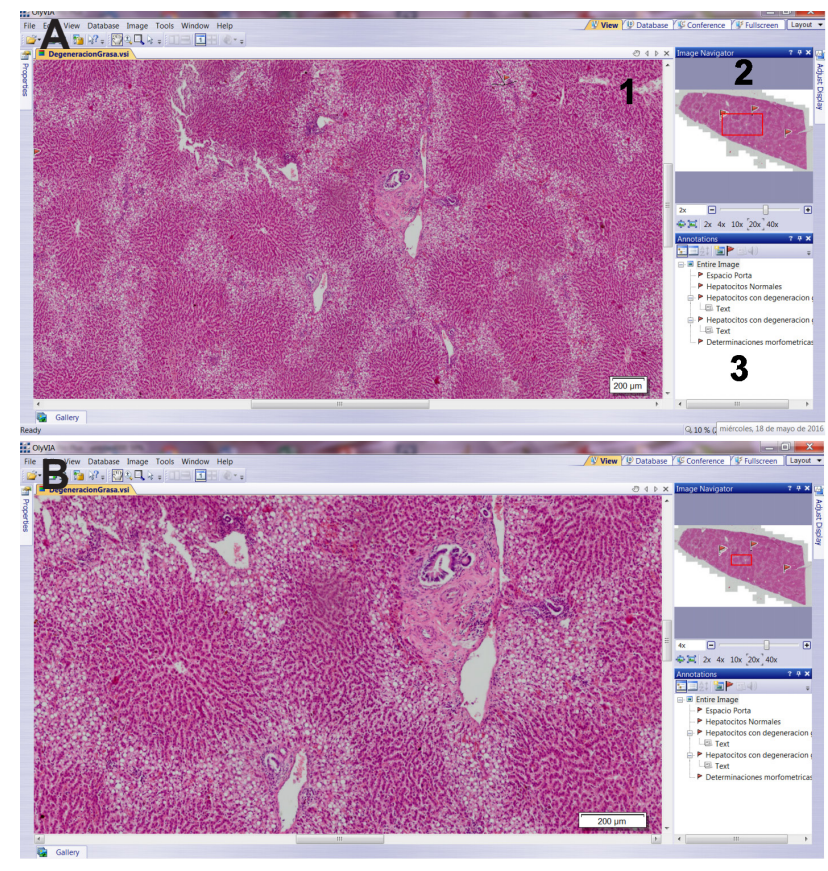

La MV presenta muchas ventajas en relación a la microscopía convencional, entre ellas:

1) Solo se requiere un microscopio para escanear la muestra. Una vez digitalizada, la imagen puede ser enviada a todo el mundo a través de internet o por medios electrónicos de almacenamiento y observadas en cualquier computadora.

2) Los estudiantes pueden observar la imagen de manera simultánea y en el horario que prefieran.

3) La muestra no necesita ser trasladada desde su lugar de procesamiento para su observación evitando, de esa manera, su extravío o ruptura.

4) La imagen digital permite señalar diferentes estructuras y guardarlas en el mismo archivo.

5) Permite realizar estudios morfométricos sin la necesidad de contar con una regla micrométrica, ya que al escanearse se almacena su calibración espacial junto con la imagen.

6) Las imágenes digitales se mantienen estables a lo largo del tiempo, en tanto los cortes montados en portaobjetos pueden decolorarse.

7) La imagen digital solo ocupa un pequeño espacio dentro de un soporte informático, mientras
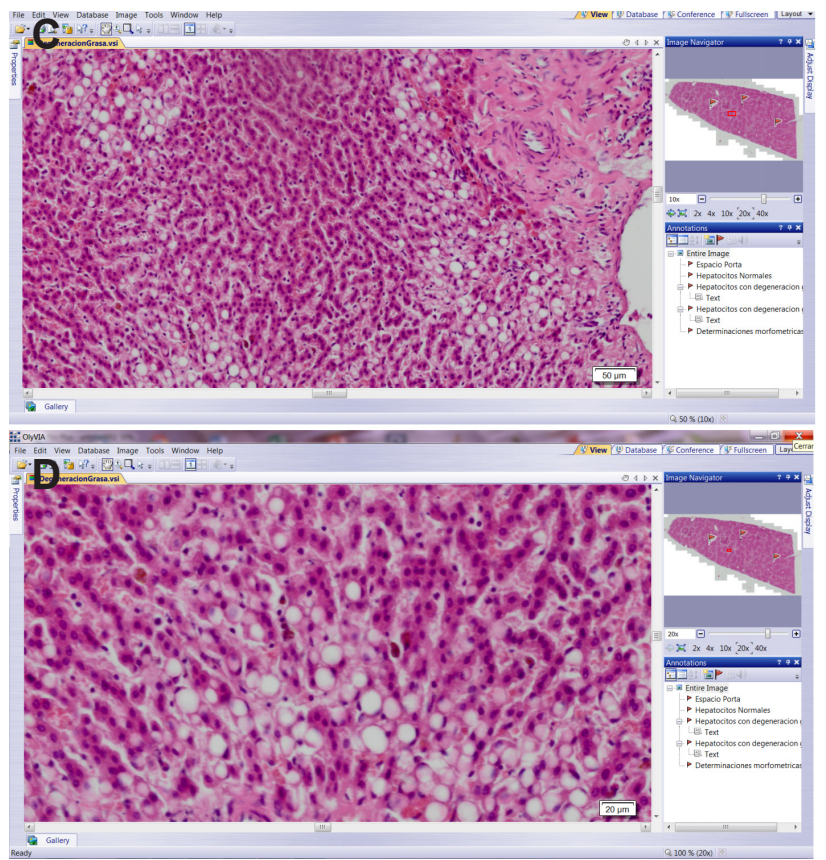

Figura 3. Visualizador de imágenes encadenadas. El programa OlyVIA permite observar distintos aumentos de la imagen escaneada. La pantalla principal del programa se divide en tres sectores. El primero (1) muestra la imagen del tejido en sus distintos aumentos. El sector (2) muestra todo el tejido escaneado y circunscribe en rojo la parte del tejido que se muestra en (1). En el sector (3) se pueden ingresar comentarios acerca de los objetos que se observan en la muestra y se los identifica mediante banderas, las que también se observan en la imagen del sector (2). Esto permite que todos los estudiantes identifiquen los mismos objetos y reconozcan sus características. En esta figura, se observa un corte de hígado, sufriendo un proceso de degeneración grasa. Los aumentos que se observan son A: 2X, B: 4X, C:10X y D: 20X. 
que los cortes montados en portaobjetos ocupan un espacio físico considerable.

A raíz de la relevancia que genera este tipo de método, se han desarrollado nuevos hardware y software específicos para tal fin (McCullough et al., 2004). Esta herramienta se utiliza desde hace un año en el curso de Patología General de nuestra carrera. De acuerdo con la encuesta realizada oportunamente (Migliorisi et al., 2016; Santelices Iglesias et al., 2016), la implementación de la MV tuvo un alto grado de satisfacción entre los estudiantes del curso.

Se trata, entonces, de una herramienta relevante y prometedora que tiene una gran utilidad, no sólo docente, sino también en la investigación y en el diagnóstico.

\section{Conflicto de intereses}

Los autores declaran que no existe conflicto de intereses, relaciones financieras, personales o de otro tipo con personas u organizaciones que pudieran afectar al presente trabajo.

\section{Bibliografía}

García Rojo M, Ferreres LA. Telepatología dinámica. En: Ferreres LA, Rojo MG, 2001. Manual de telepatología. Pamplona; Sociedad Española de Anatomía Patológica, pp. 103-46.

Figueroa C, Díaz E, Bosco C, Rojas R, Grabe N, Gutiérrez S, López J, García A, Hartel S. 2015. Microscopía virtual: tecnología al servicio de la enseñanza de la Histología/Embriología en cursos de ciencias de la salud. http://documentos.redclara.net/handle/10786/979 accedido el $1 / 3 / 2016$.

McCullough B, Ying X, Monticello T, Bonnefoi M. 2004. Digital microscopy imaging and new approaches in toxicologic pathology. Toxicologic pathology. 32(2):49-58.

Migliorisi AL, Santelices Iglesias OA, Wright C, Grandinetti JAB, Paulovich FB, Saturno PD, Nishida F, Granero Agüero JM, Fontana C, Scenna GS, Sisti MS, Camiña AE, Portiansky EL. Implementación de un microscopio virtual para la enseñanza en el curso de Patología General Veterinaria. Primeras Jornadas sobre las Prácticas Docentes en la Universidad Pública. Dirección de Capacitación y Docencia y la Especialización en Docencia Universitaria. Secretaría de Asuntos Académicos de la UNLP. Abril de 2016.

Mikula S, Trotts I, Stone JM, Jones EG. 2007. Internetenabled high-resolution brain mapping and virtual microscopy. Neuroimage. 35(1):9-15.

Peña Amaro J. Competencias y habilidades en histología médica: el potencial formativo de la observación microscópica. Res Novae Cordubenses IV. Estudios de calidad e Innovación de la Universidad de Córdoba. 2007; 4:31-46.

Portiansky EL. Análisis multidimensional de imágenes digitales. 2013. 1a ed. La Plata. Universidad Nacional de La Plata.

Salinas J. 2010. ¿Qué aportan las tecnologías de la información y la comunicación a las universidades convencionales?
Algunas consideraciones y reflexiones. Revista Educación y Pedagogía. 14(33):89-105.

Santelices Iglesias OA, Wright C, Grandinetti JAB, Migliorisi AL, Paulovich FB, Saturno PD, Nishida F, Granero Agüero JM, Fontana C, Scenna GS, Sisti MS, Camiña AE, Portiansky EL. Microscopía virtual como recurso didáctico en actividades presenciales. Primera Jornada de Tecnologías de la Información y la Comunicación (TIC). Facultad de Ciencias Veterinarias. Universidad Nacional de La Plata. Marzo de 2016. 